\title{
Nestin depletion induces melanoma matrix metalloproteinases and invasion
}

\author{
Chung-Wei Lee ${ }^{1}$, Qian Zhan ${ }^{1}$, Cecilia Lezcano ${ }^{1}$, Markus H Frank², John Huang ${ }^{1,3}$, Allison R Larson ${ }^{1}$, Jennifer Y Lin ${ }^{4}$, \\ Marilyn T Wan ${ }^{1,4}$, Ping-I Lin ${ }^{5}$, Jie Ma ${ }^{2}$, Sonja Kleffel ${ }^{4}$, Tobias Schatton ${ }^{4}$, Christine G Lian ${ }^{1}$ and George F Murphy ${ }^{1}$
}

Matrix metalloproteinases (MMPs) are key biological mediators of processes as diverse as wound healing, embryogenesis, and cancer progression. Although MMPs may be induced through multiple signaling pathways, the precise mechanisms for their regulation in cancer are incompletely understood. Because cytoskeletal changes are known to accompany MMP expression, we sought to examine the potential role of the poorly understood cytoskeletal protein, nestin, in modulating melanoma MMPs. Nestin knockdown (KD) upregulated the expression of specific MMPs and MMP-dependent invasion both through extracellular matrix barriers in vitro and in peritumoral connective tissue of xenografts in vivo. The development of three-dimensional melanospheres that in vitro partially recapitulate noninvasive tumorigenic melanoma growth was inhibited by nestin KD, although ECM invasion by aberrant melanospheres that did form was enhanced. Mechanistically, nestin KD-dependent melanoma invasion was associated with intracellular redistribution of phosphorylated focal adhesion kinase and increased melanoma cell responsiveness to transforming growth factor-beta, both implicated in pathways of melanoma invasion. The results suggest that the heretofore poorly understood intermediate filament, nestin, may serve as a novel mediator of MMPs critical to melanoma virulence. Laboratory Investigation (2014) 94, 1382-1395; doi:10.1038/labinvest.2014.130; published online 3 November 2014

Matrix metalloproteinases (MMPs) are endopeptidases involved in dissolution and remodeling of extracellular matrix (ECM) elements. Accordingly they have important roles in physiological processes, such as embryogenesis and tissue repair, as well as in multistep cancer progression where tumorigenic cells in primary lesions acquire the ability to infiltrate connective tissue and ultimately to metastasize. ${ }^{1}$ In melanoma, an established model for tumor progression, ${ }^{2}$ MMPs and their tissue inhibitors (TIMPs) are expressed in both tumor cells and tumor stroma, and these two compartments are believed to collaborate in facilitating infiltration of malignant cells through ECM and away from the main tumor nodule. ${ }^{3}$ This model is most relevant to the concept of vertical growth of primary melanoma where cells both aggregate as expansive nodules driven by self-renewing cells ${ }^{4}$ and/or may infiltrate into surrounding dermis where they associate with vessels that communicate with lymph nodes and/or the peripheral circulation. ${ }^{1,3,4}$ Thus, both tumorigenic and infiltrative growth patterns are important and complementary facets of melanoma virulence, ${ }^{1,3,4}$ both at primary sites where subsets of tumorigenic cells of the vertical growth phase invade stroma and seek access to vessels, and at metastatic loci where migrant cells endeavor to reform tumor nodules, thus creating durable metastases.

Multiple signaling pathways are involved in molecular regulation of MMPs, ${ }^{5}$ with cytoskeletal alterations most recently implicated. ${ }^{6}$ In this regard, melanomas express a physiologic stem cell and tumor virulence-associated type VI intermediate filament cytoskeletal protein, nestin, the function of which in cancer remains incompletely understood. ${ }^{7}$ Although nestin is a molecule normally associated with neural crest stem cells ${ }^{8}$ and has been advanced as a melanoma stem cell/initiating cell marker, ${ }^{7,9}$ the cellular localization of nestin in most melanomas, in our experience, is more ubiquitous than that seen in the more discrete and infrequent subsets defined by conventional biomarkers such as ABCB5 and CD271 that identify rigorously defined self-renewing cells capable of pluripotency. ${ }^{10,11}$ Accordingly, we posited that the functional role of nestin in melanoma may differ from that of conventional cancer-initiating

\footnotetext{
'Department of Pathology, Brigham and Women's Hospital and Harvard Medical School, Boston, MA, USA; ${ }^{2}$ Transplantation Research Center, Children's Hospital and Brigham and Women's Hospital, Harvard Medical School, Boston, MA, USA; ${ }^{3}$ Department of Surgery, National Taiwan University Hospital, Taipei, Taiwan; ${ }^{4}$ Department of Dermatology, Brigham and Women's Hospital and Harvard Medical School, Boston, MA, USA and ${ }^{5}$ Division of Biostatistics and Epidemiology, Cincinnati Children's Hospital Medical Center, Cincinnati, OH, USA

Correspondence: Dr GF Murphy, MD, Department of Pathology, Brigham and Women's Hospital, 75 Francis Street, Boston, MA 02115, USA.

E-mail: gmurphy@rics.bwh.harvard.edu
}

Received 27 May 2014; revised 25 July 2014; accepted 8 September 2014 
cells. ${ }^{12,13}$ Supporting this notion, experimental nestin depletion recently has been shown to be associated with invasiveness of prostate carcinoma cells. ${ }^{14}$ We thus initially screened two nestin-expressing and nestin knockdown (KD) melanoma cell lines for genes associated with invasion/ epithelial mesenchymal transition. Among genes analyzed, nestin depletion (as originally observed by one of us, QZ), was most significantly associated with the upregulation of MMP expression, leading to the series of experiments and related observations reported herein. Our data suggest that nestin is an important regulator of MMP expression and the invasive phenotype in melanoma, and that multiple pathways may converge to influence this nestin/MMP axis.

\section{MATERIALS AND METHODS Study Design}

Association between nestin sub-cellular distribution and melanoma growth patterns was initially explored in 10 primary cutaneous melanomas (5 nodular and 5 infiltrative/ desmoplastic) and further confirmed in a total of 153 cases of primary and metastatic melanomas. To investigate the function of nestin in modulating melanoma tumorigenic versus infiltrative growth, mRNA levels of metastasis-related genes including MMPs were compared in two melanoma cell lines with stable nestin gene knockdown. Subsequent analyses of nestin expression and melanoma growth patterns were performed in in vitro cell migration, invasion and spherogenic growth assays, and in in vivo tumorigenic growth and invasion assays using mouse xenograft models.

\section{Human Melanoma Specimens}

The use of human melanoma specimens was approved by the Institutional Review Board of the Brigham and Women's Hospital. Five purely nodular and five infiltrative/desmoplastic melanomas were screened from patients who underwent surgery. An additional 153 cases of primary and metastatic melanomas demonstrating clear nodular or infiltrative growth patterns were evaluated for nestin expression in melanoma tissue microarrays (TMA) purchased from Folio Bio (Powell, OH, USA), US Biomax (Rockville, MD, USA), and Imgenex (San Diego, CA, USA). All cases were confirmed by a board-certified dermatopathologist (GFM). In the TMA, nodular growth patterns involved coalescent, cohesive, and expansive regions formed primarily by rounded, epithelioid melanoma cells, whereas infiltrative growth patterns consisted of dyshesive nests, fascicles, and single cells that were often elongated to fusiform and that intermingled with and infiltrated through stroma. Although some of those with nodular growth patterns may have been melanomas of the so-called nodular vertical growth-phase subtype, and some of those with infiltrative growth patterns may have represented more desmoplastic/sarcomatoid vertical growthphase variants, the TMA was not annotated such that these distinctions used in diagnostic classification could be made.

\section{Routine Histology}

All human and mouse melanoma specimens were formalinfixed, paraffin-embedded, sectioned, and stained with hematoxylin and eosin (H\&E) for histopathological evaluation.

\section{Immunohistochemistry and Immunofluorescence Staining}

Immunohistochemistry and immunofluorescence staining was performed according to a standard protocol. ${ }^{13,15}$ Sections were treated with heat-induced epitope retrieval using target retrieval solution (Dako, Carpenteria, CA, USA) and heated in a Pascal-pressurized heating chamber (Dako, $125^{\circ} \mathrm{C}$ for $30 \mathrm{~min}, 90^{\circ} \mathrm{C}$ for $10 \mathrm{~min}$ ). After incubation with primary antibodies at $4{ }^{\circ} \mathrm{C}$ overnight, sections were incubated with HRP-conjugated secondary antibodies for $30 \mathrm{~min}$ at room temperature, and signals were visualized with NovaRED HRP substrate (Vector Laboratories, Burlingame, CA, USA) with a hematoxylin counter stain. Alternatively, cells plated on chamber slides were fixed in $4 \%$ paraformaldehyde, penetrated with $1 \%$ Tween-20, incubated with primary antibodies at $4{ }^{\circ} \mathrm{C}$ overnight, followed by incubation with fluorophore-conjugated secondary antibodies for $30 \mathrm{~min}$ at room temperature. Isotype-matched immunoglobulin was used in place of primary antibodies as controls. Antibodies against human nestin ${ }^{16}$ (1:200, Millipore, Billerica, MA, USA, MAB5326), MMP3 $^{17}$ (1:50, Abcam, Cambridge, MA, USA, ab32607), SOX $2^{15}$ (1:200, Neuromics, Edina, MN, USA GT15098), phospho-FAK (pT397) ${ }^{18}$ (1:50, Cell Signaling, Danvers, MA, USA, D20B1), and mouse F4/80 ${ }^{19}$ (1:200, AbD Serotec, MCA497GA) and CD31 ${ }^{20}$ (1:100, Abcam, ab28364) were used. MMP3 expression in melanoma cells was quantified by microdensitometry using ImageJ. Nestin staining was qualitatively evaluated as diffuse cytoplasmic (a pattern that produced apparently stronger reactivity and that characterized more rounded melanoma cells that grew in cohesive and expansive nodules), and sub-plasma membranous (a pattern that resulted in apparently weaker reactivity and that tended to be restricted to more elongated to fusiform melanoma cells, showing stromal infiltration). Subcellular patterns of phosphorylated focal adhesion kinase (pFAK) redistribution were quantified as previously described. ${ }^{18}$

\section{Cell Culture}

Human melanoma cell A2058 and A375 and transformed human embryonic kidney cell HEK293T lines were originally obtained from American Type Culture Collection (Manassas, VA, USA). Cells were recently confirmed to have no mycoplasma contamination by PCR. ${ }^{21}$ All cells were grown in Dulbecco's Modified Eagle's Medium (DMEM, Lonza, Hopkinton, MA, USA). Culture media were supplemented with $10 \%$ heat-inactivated fetal bovine serum (FBS, HyClone), $200 \mathrm{mM}$ L-glutamine, $100 \mathrm{IU} / \mathrm{ml}$ penicillin, and $100 \mu \mathrm{g} / \mathrm{ml}$ streptomycin (P/S/G, Life Technologies, Carisbad, CA, USA), and maintained at $37^{\circ} \mathrm{C}, 5 \% \mathrm{CO}_{2}$. If not otherwise stated, subconfluent cell culture was treated with $0.25 \%$ 
trypsin/EDTA solution (Hyclone) at $37^{\circ} \mathrm{C}$ for $1-2 \mathrm{~min}$. Single cells were washed and resuspended in complete medium and stained with trypan blue. Viable cells were counted under a hemocytometer and seeded on tissue culture plates. Cells were treated with transforming growth factor-beta (TGF- $\beta$ ) (Peprotech, Rocky Hill, NJ) at $5 \mathrm{ng} / \mathrm{ml}$ for 3 days or FAK inhibitor PF-573228 (Sigma-Aldrich, St Louis, MO) at $1 \mu \mathrm{M}$ for $24 \mathrm{~h}$ and harvested for analysis.

\section{Knockdown of Nestin}

Nestin expression was knocked down by a lentivirus-based shRNA approach. shRNA vectors specifically targeting nestin (TRCN000014728 and TRCN000014729) were purchased (Sigma-Aldrich). A non-targeting, scramble vector (SHC002, Sigma-Aldrich) or eGFP-targeting vector (SHC005, SigmaAldrich) was used as vector control (Vec). shRNA lentiviruses were produced in HEK293T cells by co-transfecting shRNA vectors with packaging vectors $\mathrm{pHR}$ '8.2dR and pCMV-VSV$\mathrm{G}$ (gifts from Robert A. Weinberg, Whitehead Institute) into subconfluent HEK293T cells with FuGENE 6 (Promega, Madison, WI, USA) as described before. ${ }^{15}$ Viral supernatant was collected at $48 \mathrm{~h}$ post transfection and passed through $0.45-\mu \mathrm{m}$ filters to remove cell debris. In total, $5 \times 10^{4}$ target cells were seeded in each well of six-well culture plates. After overnight culture, cells were transfected with $2 \mathrm{ml}$ of viral supernatant containing nestin-targeting shRNA or control vectors in the presence of polybrene $(8 \mu \mathrm{g} / \mathrm{ml})$ for $8 \mathrm{~h}$, and allowed to recover in complete media. Twenty-four hours post transfection, transduced cells were selected with puromycin $(1 \mu \mathrm{g} / \mathrm{ml})$. Efficacy of nestin KD was assessed by quantitative RT-PCR and western blot. Among the shRNA vectors examined, TRCN000014728 targeting nestin 3'-UTR gave the highest $\mathrm{KD}$ efficiency and was routinely used in this study. To exclude the possibility of off-target effects of shRNA, nestin-specific shRNA vectors TRCN000014729 was used to validate the effect on downstream gene expression.

\section{Gene Expression Analysis}

Total RNA was extracted (RNeasy mini Kit, Qiagen, Valencia, CA, USA) from adherent vector control, nestin KD cells, and melanoma spheres in spherogenic culture. cDNA was synthesized from total RNA using SuperScript III First-strand Synthesis System (Invitrogen, Carisbad, CA, USA) and served as the template for gene expression analysis. Relative expression of 84 genes involved in cell migration and metastasis were compared between A2058 Vec control and nestin KD cells using a human tumor metastasis PCR Array (PAHS028A, SABiosciences, Frederick, MD, USA). Results from the PCR array were further validated by real-time quantitative RT-PCR in triplicate using Applied Biosystems 7300 system (Foster City, CA) and the $\Delta \Delta \mathrm{Ct}$ analysis method as reported previously. ${ }^{15}$ Taqman quantitative PCR primers of human nestin (Hs00707120_s1), SOX2 (Hs00602736_s1), OCT4 (Hs00742896_s1), CD271 (Hs00609976_m1), MMP2 (Hs01548727_m1), MMP3 (Hs00968305_m1), MMP9
(Hs00234579_m1), TIMP1 (Hs00171558_m1), TIMP2 (Hs00234278_m1), and actin (4310881E) were purchased from Applied Biosystems. Primers of MMP1, MMP7, MMP10, MMP11, MMP13, TIMP3, TIMP4, and GAPDH were designed in house for SYBR Green quantitative PCR reaction (Supplementary Table S1). Changes of mRNA levels more than twofold were considered significant.

\section{Western Blot}

Subconfluent cell cultures and culture medium were collected for western blotting analysis. Adherent cells were treated with non-enzymatic cell dissociation buffer Versene (Life Technologies), collected, washed twice with PBS, and lysed in cell lysis buffer (Cell Signaling) containing proteinase inhibitor cocktail and PMSF. Protein content was determined by bicinchoninic acid assay kit (Thermo Scientific, Rockford, IL). An equal amount of total proteins in cell lysate $(100 \mu \mathrm{g})$ and $50 \mu \mathrm{l}$ cell culture medium (equivalent to $2 \times 10^{5}$ viable cells $/ \mathrm{ml})$ was separated on SDS-PAGE $(4-12 \%$ Bis-Tris, Invitrogen) at 100 volts at $4{ }^{\circ} \mathrm{C}$ for $3.5 \mathrm{~h}$, transblotted onto nitrocellulose membrane at $340 \mathrm{~mA}$ at $4{ }^{\circ} \mathrm{C}$ for $1.5 \mathrm{~h}$, and blocked with 5\% non-fat milk in TBS/0.1\% Tween 20 (TBST) at room temperature for $1 \mathrm{~h}$. The membrane was incubated with primary antibodies at $4{ }^{\circ} \mathrm{C}$ overnight with constant shaking. After washing three times for $5 \mathrm{~min}$ in TBST, the membrane was incubated with horseradish peroxidase (HRP)-conjugated secondary antibodies at room temperature for $30 \mathrm{~min}$, washed again with TBST three times, and immunoreactive bands were detected by chemiluminescent reagents (Thermo Scientific) according to manufacturer's protocol. Chemiluminescence was visualized using CL-XPosure film (Thermo Scientific) or ChemiDoc XRS (Bio-Rad). Densities of immunoblot bands were quantified by Image J and normalized to $\beta$-actin. Antibodies for the western blot were commercially available for mouse antinestin $^{22}$ (1:1000, Millipore, MAB5326, clone 10C2), rabbit anti-MMP1 (1:1000, Abgent, AP11874c, clone RB18908, San Diego, CA), rabbit anti-MMP3 ${ }^{23}$ (1:1000, Abcam, ab53015), mouse anti-MMP924 (1:1000, Abcam, ab58803, clone 56-2A4), anti-MMP10 ${ }^{25}$ (1:1000, Abcam, ab28206), rabbit anti-FAK ${ }^{18}$ (1:1000, Cell Signaling, \#3285), rabbit anti-phospho-FAK (pT397), ${ }^{18}$ (1:1000, Cell Signaling, D20B1), and mouse anti$\beta$-actin ${ }^{26}$ (1:10 000, Abcam, ab6276, clone AC-15).

\section{Cell Proliferation Analysis}

To measure cancer cell proliferation in adherent monolayer culture, 100000 viable cells/well were seeded on 6-well tissue culture plates in six replicates. Viable cells were quantified by trypan blue exclusion using a hemocytometer at $72 \mathrm{~h}$.

\section{Melanoma Cell Culture on Matrigel}

Matrigel ( $50 \mu$ l, Dickinson Bioscience, Bedford, MA, USA) was spotted onto $6-\mathrm{cm}$ cell culture plates and allowed to set at $37^{\circ} \mathrm{C}$ for $2 \mathrm{~h}$. A2058 cells $\left(2 \times 10^{3}\right.$ viable cells per $10 \mu \mathrm{l}$ complete medium) were loaded over Matrigel, incubated at 
$37^{\circ} \mathrm{C}, 5 \% \mathrm{CO}_{2}$ for $2 \mathrm{~h}$, overlaid with complete medium and cultured for 10 days. Cells on Matrigel were fed with $0.5 \mathrm{ml}$ of fresh medium twice a week. ${ }^{27}$ Melanoma spheres on Matrigel were fixed with formalin and embedded in paraffin. Sections perpendicularly across Matrigel were stained with $\mathrm{H} \& \mathrm{E}$ and photographed for histological analysis. Spheres with $<20 \%$, $20-100 \%$, and $100 \%$ of sphere depth invading into Matrigel surface were defined as surface, partial invasion, and complete invasion into Matrigel, respectively. Numbers of melanoma spheres that invaded into Matrigel were counted and compared by a $\chi^{2}$-test.

\section{Anchorage-Independent Cell Culture}

Anchorage-independent spherogenic cell culture ${ }^{28}$ was performed in suspension or in soft agar culture with the culture medium devoid of epidermal growth factor and basic fibroblast growth factor, which may potentially alter nestin expression. ${ }^{29,30}$ For melanosphere culture in suspension, melanoma cells were cultured at low cell-plating density (2000 viable cells per 6 well or 1000 viable cells per 24 well) in DMEM supplemented with $10 \% \mathrm{FBS}, \mathrm{P} / \mathrm{S} / \mathrm{G}$, and $0.5 \%$ methyl cellulose (Sigma-Aldrich) in the ultra-low attachment plates (Corning, Acton, MA, USA), and maintained at $37^{\circ} \mathrm{C}$, $5 \% \mathrm{CO}_{2}$ for 14-21 days. Melanoma spheres were fed with $0.5 \mathrm{ml}$ of fresh medium twice a week. Serial passage of melanoma spheres was performed to confirm in vitro selfrenewal capability. Melanoma spheres were dissociated with $0.25 \%$ trypsin/EDTA solution at $37^{\circ} \mathrm{C}$ for $3-5 \mathrm{~min}$, and single cells derived from melanoma spheres were plated in the ultra-low attachment plates and allowed to form secondary spheres for 14 days. For soft agar culture, a six-well plate was covered with DMEM medium containing $10 \% \mathrm{FBS}, \mathrm{P} / \mathrm{S} / \mathrm{G}$, and $1 \%$ agar noble (BD Biosciences, San Jose, CA, USA), overlaid with 25000 viable cells in culture medium containing $0.4 \%$ agar at $37^{\circ} \mathrm{C}, 5 \% \mathrm{CO}_{2}$ for $28-35$ days. Soft agar colonies were fed with $1 \mathrm{ml}$ of fresh medium containing $0.35 \%$ agar weekly. Spheres and colonies were stained with $200 \mu \mathrm{l}$ of $0.4 \% \mathrm{p}$-iodonitrotetrazolium violet (Sigma-Aldrich) overnight and photographed by a Canon T1i camera and Sigma $50 \mathrm{~mm} / \mathrm{f} 2.8$ macro lens. Numbers of spheres and colonies from triplicate experiments were counted by ImageJ (National Institutes of Health, ver. $1.44 \mathrm{k}$ ).

\section{Cell Migration Analysis}

BioCoat 24-well control inserts (Becton Dickinson Bioscience) were used for tumor migration analysis. Vector control and nestin KD cells were collected from subconfluent cultures by Versene (Life Technologies), washed with PBS, and resuspended in loading media of DMEM containing $0.1 \%$ bovine serum albumin. Single-cell suspension were stained with trypan blue and counted under a hemocytometer. $1 \times 10^{4}$ viable cells in $0.2 \mathrm{ml}$ of loading media were loaded onto control inserts, $0.75 \mathrm{ml}$ of DMEM containing $10 \%$ FBS was added to the outer well immediately, and incubated at $37^{\circ} \mathrm{C}, 5 \% \mathrm{CO}_{2}$ for 4,6 , and $8 \mathrm{~h}$. After incubation, unwanted cells were removed by scrubbing, and cells on the other side of the control insert membrane were fixed by $10 \%$ formalin and stained with hematoxylin and $0.1 \%$ ammonium hydroxide. Cell counting was facilitated by photographing at three randomly selected fields at $10 \times$ magnification on each control insert membrane. Six replicates were set up for each cell line; migrating cells (on the lower surface of control insert membranes) and non-migrating cells (on the upper surface of control insert membranes) were counted in triplicate. To control loading error, percent cell migration through the control insert was calculated by dividing the mean number of migrating cells by total cell number loaded (sum of migrating cells and non-migrating cells). A twosample Z-test was used to assess whether the probability of cell migration in nestin $\mathrm{KD}$ groups differed from vector control groups. A $P$-value $<0.05$ is considered significant.

\section{Matrigel Invasion Analysis}

BioCoat control inserts and growth factor-reduced Matrigel invasion chambers (Becton Dickinson Bioscience) were used for invasion assays as described previously. ${ }^{15}$ Vector control and nestin KD cells were prepared as mentioned above in the migration analysis. $1 \times 10^{4}$ viable cells in $0.2 \mathrm{ml}$ of loading media and $2.5 \times 10^{4}$ viable cells in $0.5 \mathrm{ml}$ of loading media were loaded onto a control insert and a Matrigel insert, respectively, and $0.75 \mathrm{ml}$ of DMEM containing $10 \%$ FBS was added to the outer well immediately and incubated at $37^{\circ} \mathrm{C}, 5 \% \mathrm{CO}_{2}$ for $20 \mathrm{~h}$. After incubation, non-migrating cells were removed from the upper surface of insert membranes by scrubbing, and migrating cells on the lower surface of insert membranes were stained and counted as mentioned above. Triplicates were set up in control and Matrigel inserts for each cell line. To characterize the function of MMP enzymatic activities in Matrigel invasion of A2058 and A375 nestin KD cells, MMP3-selective inhibitor UK356618 (Tocris, Bristol, UK) at $20 \mathrm{nM}\left(\mathrm{IC}_{50}=5.9 \mathrm{nM}\right)^{31}$ and the broadspectrum MMP inhibitor Marimastat (Tocris) at $20 \mathrm{nM}$ $\left(\mathrm{IC}_{50}=5,6,3,13\right.$, and $9 \mathrm{nM}$ for MMP-1, 2, 9, 7, and 14, respectively) ${ }^{32}$ were added to the loading media within the insert and complete media in the outer well. These two MMP inhibitors were selected because of their potent inhibitory activities and no known cytotoxicity or adverse effect on cell proliferation. ${ }^{32}$ To control the difference in cell migration and loading error, percent Matrigel invasion was calculated by dividing the mean number of migrating cells on the lower surface of Matrigel invasion chambers by the mean number of migrating cells on the lower surface of the control inserts.

\section{Mouse Xenograft and Histological Analysis}

Specific pathogen-free, female NOD.CB17-Prkdc $c^{\text {scid } / J ~(N O D / ~}$ SCID) or male NOD.Cg-Prkdscid Il2rg ${ }^{\text {tm } 1 \text { Wjl }} /$ SzJ (NSG) mice were originally purchased from the Jackson Laboratory (Bar Harbor, ME, USA) and were maintained in accordance with the institutional guidelines of Children's Hospital Boston and Harvard Medical School. Experiments were performed 
according to approved experimental protocols. ${ }^{33,34}$ A2058 vector control and nestin KD cells derived from subconfluent monolayer culture were injected subcutaneously into the flanks of mice at 6-8 weeks of age. To ensure tumor formation for evaluation of tumor invasion into stroma and macrophage, and vascular invasion into tumors, and diminish the potential influence of KD in xenograft tumor formation due to changes in the frequency of malignant melanoma initiating cells ${ }^{13}$ melanoma cells were injected into both flanks of NSG and right flanks of NOD-SCID mice at $1 \times 10^{6}(N=16$ injections per cell line, two injections each mouse) and $3 \times 10^{6}(N=5$ injections per cell line, one injection each mouse) viable cells in $100 \mu$ l PBS, respectively. Sample sizes of animal studies and cell numbers injected were based on pilot studies and previously published approaches ${ }^{10,35}$ by our laboratory, as the differences evaluated focused on qualitative parameters involving detection of invasion and protein expression based on immunohistochemistry. No animals were excluded from analysis. Tumor size was measured weekly with a caliper and tumor volume was calculated as $3.14 / 6 \times \mathrm{L} \times \mathrm{W} \times \mathrm{W}$. Mice were killed on 7, 14, and 20 days (NSG mice), or on 28 days (NOD/SCID) post tumor inoculation. Tumors were fixed in formalin and embedded for histological analysis. Investigators were not blinded to group allocation during the experiment or when assessing initial outcomes. However, to further validate outcome when qualitative parameters were primary read-out, blinded observers were required to assign accurately the outcome parameters in a prospective manner to each of the experimental conditions.

\section{Statistical Analysis}

All experiments were technical triplicates or greater. Data were compared by two-tailed Student's $t$-test unless otherwise stated. One-way ANOVA test with Tukey's multiple comparison was used when more than two samples were compared. Nestin distribution in nodular and infiltrative patient melanoma and nestin subcellular distribution were compared by $\chi^{2}$-test. Statistical analysis was performed using GrapdPad Prism 5 (GrapdPad Software Inc., La Jolla, CA, USA). Data are presented as mean \pm s.e.m. A $P$-value $<0.05$ is considered significant.

\section{RESULTS}

\section{Nestin Affects Melanoma MMP Expression}

We initially produced nestin KD lines in A2058 and A375 cells, one derived from primary skin melanoma (A375), one from lymph node metastasis (A2058). ${ }^{36}$ Nestin mRNA levels, averaged over a minimum of four replicate determinations, were significantly downregulated in nestin $\mathrm{KD}$ cells of A2058 $(89.5 \%$ decrease, $P<0.001)$ and A375 $(91.4 \%$ decrease, $P<0.001)$ lines, as compared with vector controls (Figure 1a). Decreased nestin protein levels were confirmed in nestin KD A2058 (92.7\% decrease) and A375 (97.7\% decrease) cells as compared with vector control cells by

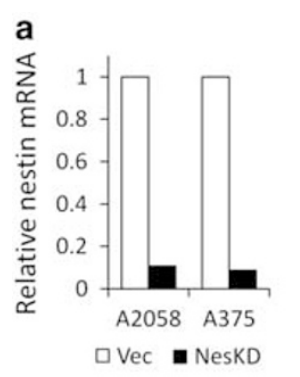

b

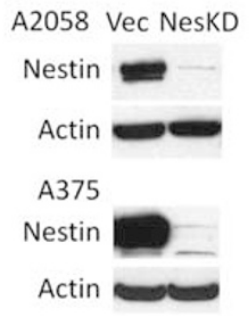

d

A2058

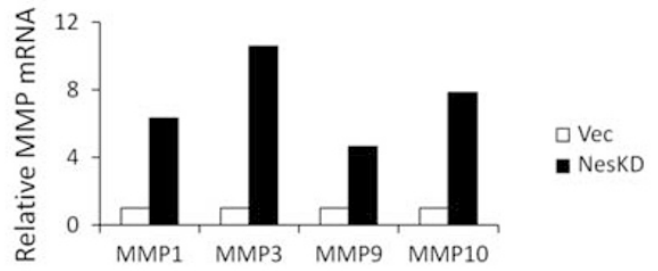

e

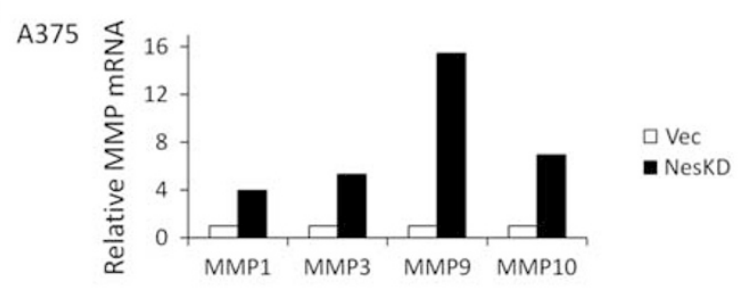

$\mathbf{f}$

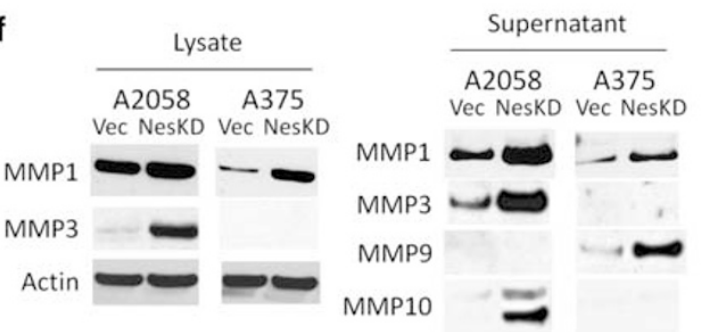

Figure 1 Nestin affects melanoma MMP expression. (a) Nestin mRNA levels were significantly downregulated in nestin KD cells (NesKD, black bars) of A2058 (89.5\% decrease) and A375 (91.4\% decrease), as compared with vector control cells (Vec, white bars). (b) Decreased nestin protein levels were confirmed in nestin KD A2058 (92.7\% decrease) and A375 (97.7\% decrease) cells as compared with vector control cells by western blot. (c) Nestin KD did not significantly alter cell proliferation in A2058 and A375 cells. (d) Compared with A2058 vector control cells (white bars), A2058 nestin KD cells (black bars) had significantly higher mRNA levels of MMP1, MMP3, MMP9, and MMP10. (e) Compared with A375 vector control cells (white bars), A375 nestin KD cells (black bars) had significantly higher mRNA levels of MMP1, MMP3, MMP9, and MMP10. (f) Western blot confirmed that A2058 nestin KD cells had marked higher protein levels of MMP1 (3.2-fold) and MMP3 (31.2-fold) in cell lysate and secreted MMP1 (3.0-fold), MMP3 (19.9-fold), and MMP10 (60.7-fold) in supernatant. MMP9 protein in supernatant of A2058 cells was below detection limit of immunoblotting. A375 nestin KD cells had marked higher protein levels of MMP1 (7.3-fold) in cell lysate and secreted MMP1 (4.4-fold) and MMP9 (11.1-fold) in supernatant. MMP3 protein in cell lysate and supernatant of A375 cells were below detection limit of immunoblotting. MMP9 and MMP10 proteins in cell lysate of A2058 and A375 cells were below detection limits of immunoblotting and thus data were not shown. 
western blotting (Figure 1b). Nestin KD did not significantly influence overall proliferation in bulk cultures (Figure 1c).

Because nestin expression has been shown to correlate with invasion and metastasis of certain cancers, ${ }^{7,37,38}$ we next examined the relationship between nestin and 84 tumor epithelial-mesenchymal transition/metastasis-related genes. Among these, nestin KD most profoundly affected the expression of $M M P$ genes (Figure $1 \mathrm{~d}$ and e). Specifically, mRNA levels of MMP1, 3, 9, and 10 were significantly upregulated in both A2058 and A375 lines (Figure 1d and e). Western blot analysis confirmed the upregulation of MMP1 and 3 proteins in lysates of nestin KD A2058 cells and MMP1 in nestin KD A375 cells; as well as MMP1, 3, and 10 in supernates of nestin KD A2058 cells and MMP1 and 10 in nestin KD A375 cells (Figure 1f). There was no detectable MMP9 in A2058 cells and MMP3 and 10 in A375 cells (Figure 1f). To further establish the apparent regulatory influence of nestin on MMP expression and exclude the possibility of off-target effects of nestin shRNA, additional nestin shRNA construct transfected into A2058 cells validated that mRNA levels for MMP1, 3, and 10 were significantly upregulated as a consequence of confirmed nestin $\mathrm{KD}$ (Supplementary Figure 1). There was no compensatory change in mRNA levels of tissue inhibitor of metalloproteinase 1-4 (TIMP1-4) expression with nestin $\mathrm{KD}$ in A2058 cells or in TIMP1-3 in A375 cells (data not shown). These results suggested a reciprocal relationship in the melanoma lines tested between expression of nestin and certain MMPs known to enhance tumor invasion. ${ }^{39}$

\section{Nestin KD-Associated MMP Upregulation Enhances Melanoma Invasion In Vitro}

The effects of nestin expression on cell migration and the ability of melanoma cells to traverse an ECM barrier facilitated by serum-mediated chemotaxis were next assessed. To control loading error, cells migrated through microporous transwell or Matrigel were normalized to total loaded cells or to non-Matrigel control insert, respectively. The migratory kinetics of both control melanoma cells and nestin KD melanoma cells through microporous transwell assays were similar, with increments for the first $6 \mathrm{~h}$, followed by gradual decrements thereafter, although a significantly lower percentage of nestin KD cells migrated by the 6 and $8 \mathrm{~h}$ time points (Figure 2a). However, nestin KD cells exhibited significantly greater ability to invade through ECM barriers containing collagen and basement membrane proteins (Matrigel-coated transwell membranes) when compared with vector controls after $18 \mathrm{~h}$ (Figure $2 \mathrm{~b}$ and c). Additional nestin shRNA construct transfected into A2058 cells further validated significantly enhanced Matrigel invasion in nestin KD cells and further ruled out the possibility of off-target effects of nestin shRNA on invasion (Supplementary Figure 1d). The potential contribution of MMPs to nestin KD-enhanced invasion next was addressed using the MMP3-specific inhibitor UK356618, ${ }^{31}$ which suppressed invasion of A2058 nestin $\mathrm{KD}$ cells by $33 \%$. The broad-spectrum MMP inhibitor, Marimastat, ${ }^{32}$ had a slightly greater effect (43\% inhibition), and combination of UK356618 and Marimastat resulted in further enhancement of inhibition (56\%) (Figure 2d). In A375 nestin KD cells where MMP3 protein was not upregulated in comparison with A2058 (Figure 1f), Matrigel invasion was suppressed by Marimastat by $45 \%$ but not by the MMP3 inhibitor, UK356618 (Figure 2d). These data collectively support a role for MMP induction in nestin $\mathrm{KD}$ cells in facilitating in vitro ECM invasion.

\section{Nestin KD is Associated with Decreased Sphere Formation In Vitro}

Melanospheres are three-dimensional micronodular aggregates of cohesive tumor cells that develop from melanoma cells exhibiting anchorage-independent growth. ${ }^{28}$ Melanospheres thus have been proposed to recapitulate, in part, tumorigenic growth due to self-renewing subpopulations in vivo. ${ }^{28,40}$ To determine the relationship of nestin expression to three-dimensional spherical growth potential, we generated melanospheres avoiding serum-free media that requires supplements known to influence nestin expression. ${ }^{29,30}$ Cells forming melanospheres showed selfrenewal capability confirmed by serial passage, and when compared with adherent cells, expressed mRNA for nestin, CD271, OCT4, and SOX2 $2^{7,11,35,41}$ (data not shown). Nestin KD lines had significantly decreased anchorage-independent growth and sphere-forming ability compared with their vector controls in suspension culture (Figure 2e) as well as diminished colony formation in soft agar culture. When melanospheres were grown on Matrigel membranes in the absence of a chemotactic stimulus, those that formed from nestin KD cells were irregularly sized, internally dyshesive, and depleted of immunoreactive nestin (Figure 2f). In contrast, spheres derived from vector controls were uniform in size, cohesive, and replete with strong nestin immunoreactivity (Figure 2f). Remarkably, the poorly formed nestin KD melanospheres penetrated into the Matrigel membrane, in contrast to vector control melanospheres that remained localized to the ECM surface (Figure 2f). These results suggest that nestin expression favors three-dimensional spheroidal growth that may be partially switched to a less spherogenic, more invasive phenotype as a consequence of nestin $\mathrm{KD}$.

\section{Nestin KD is Associated with Stromal Invasion In Vivo}

To test whether the in vitro relationship between nestin and MMP expression is relevant in vivo, melanoma xenografts next were evaluated. In contrast to in vitro kinetics where we noted no differences in cell proliferation between bulk cultures of nestin $\mathrm{KD}$ and vector control melanoma cells, melanoma xenograft growth may be inhibited by nestin KD when cell inoculation is limited. ${ }^{7}$ Therefore, we used relatively high-inoculation cell numbers $\left(1 \times 10^{6}\right.$ or $\left.3 \times 10^{6}\right)$ of A2058 cells calibrated to produce similar growth 
a

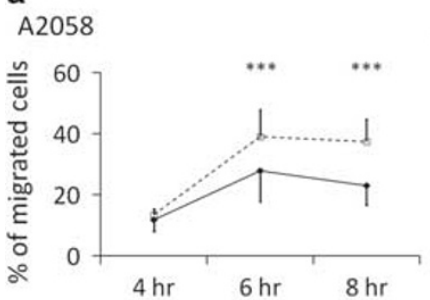

b

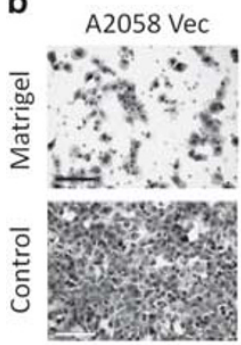

C

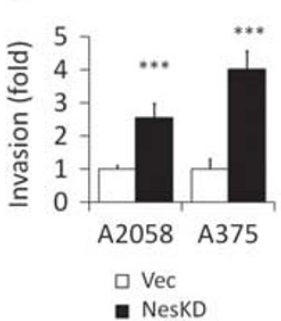

d
A375

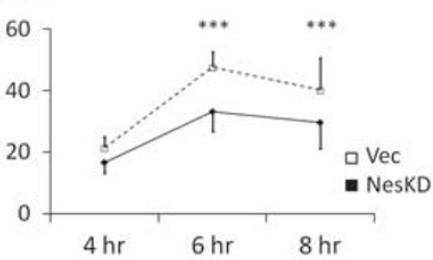

A375 Vec

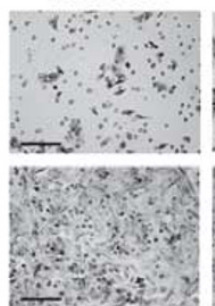

A375 NesKD
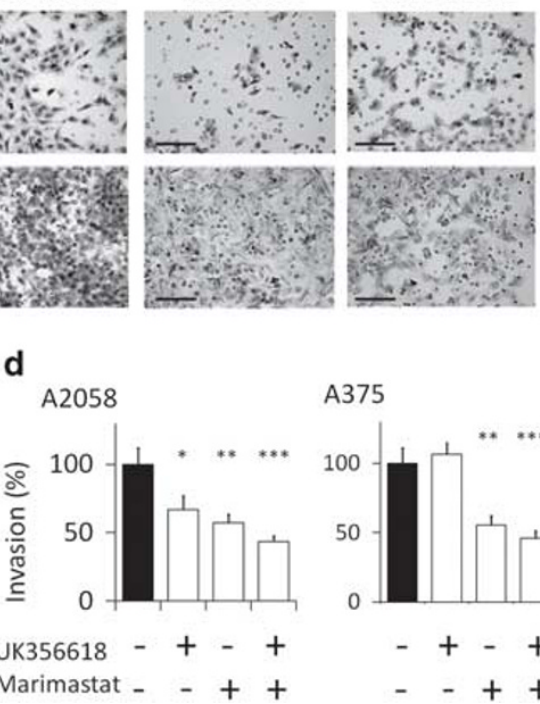

$\mathrm{A} 375$

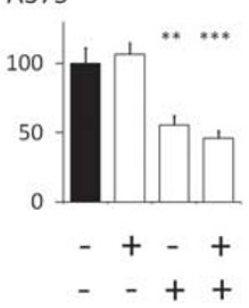

e
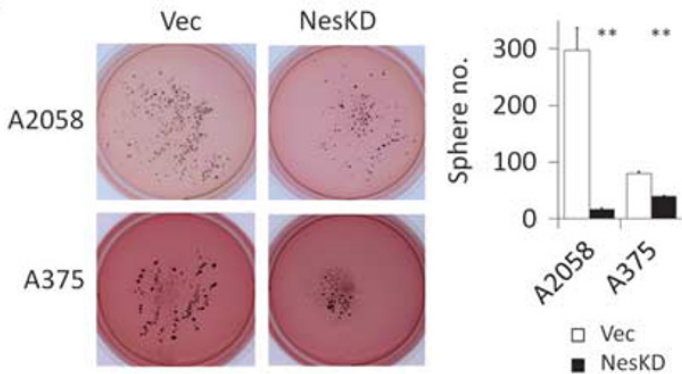

f
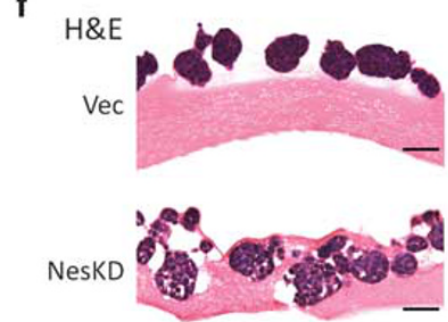

IHC: Nestin
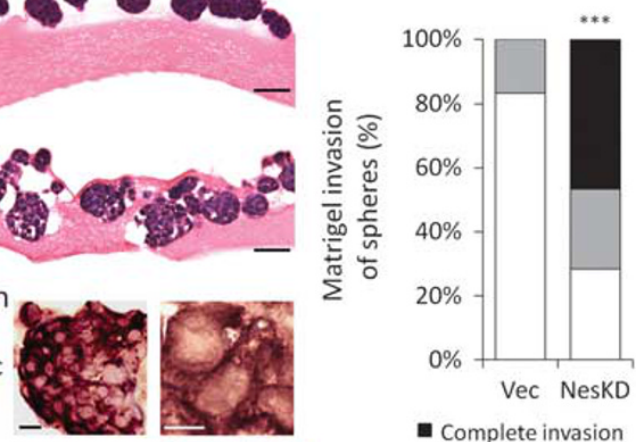

- Complete invasion

๑ Partial invasion

$\square$ Surface

Figure 2 Nestin KD enhances melanoma invasion in vitro and decreases sphere formation. (a) Significantly diminished cell migration of nestin KD cells (NesKD, solid lines) as compared with the vector control cells (Vec, dash lines) of A2058 (left; $P<0.001$ at 6 and $8 \mathrm{~h}$, respectively) and A375 (right; $P<0.001$ at 6 and $8 \mathrm{~h}$, respectively). (b) Representative fields of migrating A2058 (left) and A375 (right) cells in Matrigel inserts (top panel) and control inserts (bottom panel). Scale bars: $50 \mu \mathrm{m}$. (c) Nestin KD cells (black bars) had significantly higher Matrigel invasion than vector control cells (white bars) of A2058 (left, 2.54-fold, $P<0.001$ ) and A375 (right, 4.02-fold, $P<0.001$ ). (d) Matrigel invasion of A2058 and A375 nestin KD cells was characterized in the presence of MMP3-specific inhibitor UK356618 or the broad-spectrum MMP inhibitor Marimastat. Compared with untreated A2058 nestin KD cells (black bar), UK356618 $(20 \mathrm{nM}, 33 \%$ decrease, $P<0.05)$ and Marimastat $(20 \mathrm{nM}, 43 \%$ decrease, $P<0.01)$ significantly suppressed Matrigel invasion of A2058 nestin KD cells. Combinatorial treatment of UK356618 $(20 \mathrm{nM})$ and Marimastat ( $20 \mathrm{nM})$ additively suppressed Matrigel invasion of A2058 nestin KD cells $(56 \%$ decrease, $P<0.001)$. In addition, Matrigel invasion of A2058 nestin KD cells with combinatorial treatment of UK356618 and Marimastat was lower than monotherapy with UK356618 (65\%, $P=0.097)$. Likewise, in A375 nestin KD cells, Matrigel invasion of A375 nestin KD cells was not altered by UK356618 $(20 \mathrm{nM})$, but was significantly suppressed by Marimastat $(20 \mathrm{nM})(45 \%$ decrease, $P<0.01)$ or by combinatorial treatment of Marimastat $(20 \mathrm{nM})$ and UK356618 $(20 \mathrm{nM})(55 \%$ decrease, $P<0.001)$, as compared with untreated cells (black bar). In addition, Marimastat monotherapy and combinatorial treatment of Marimastat and UK356618 had comparable suppressive effects on A375 nestin KD Matrigel invasion. Results were compared by one-way ANOVA test with Tukey's multiple comparison test. Representative cell migration and invasion results are shown from at least three independent assays. (e) Representative images of A2058 and A375 melanospheres in spherogenic suspension culture in DMEM supplemented with $10 \%$ FBS and $0.5 \%$ methyl cellulose for 21 days. Melanospheres were visualized with p-iodonitrotetrazolium violet staining. Marked decreased of sphere formation in both A2058 (top) and A375 (bottom) nestin KD cells as compared with vector control cells (both $P<0.01$, respectively).

Representative results are shown from two independent experiments. (f) H\&E and IHC images of spheres growing over Matrigel. A2058 vector control spheres grew mainly on the surface of Matrigel (top), whereas nestin KD spheres invaded into the lattice of Matrigel (bottom). Scale bars: $50 \mu \mathrm{m}$. Location of spheres on Matrigel. Majority (83.3\%) of A2058 vector control spheres grew on the surface of Matrigel (white bar), whereas $16.7 \%$ partially invaded into Matrigel (gray bar). In contrast, $28.3 \%$ nestin KD spheres grew on the surface of Matrigel (white bar), 25\% partially invaded into Matrigel (gray bar), and $46.7 \%$ completely invaded and embedded into Matrigel (black bar). Difference in Matrigel invasion between melanospheres derived from A2058 vector control $(N=60)$ and nestin KD $(N=60)$ cells was significant $\left(P<0.0001, \chi^{2}\right.$-test). Data are represented from two independent Matrigel sphere experiments. Nestin was abundantly expressed in the cytoplasm of vector control A2058-derived melanospheres grown in association with Matrigel (top), whereas decreased nestin protein levels in nestin KD A2058-derived spheres correlated with a localized submembranous pattern (bottom, arrows). Left panels: low magnification; right panels: high magnification. Scale bars: $10 \mu \mathrm{m}$. Note: ${ }^{*} P<0.05,{ }^{* *} P<0.01,{ }^{* * *} P<0.001$.

characteristics between tumors derived from nestin $\mathrm{KD}$ and vector controls (Figure 3a) in order to control for potential effects of differential cell proliferation on MMP synthesis. ${ }^{42}$ Nestin depletion was confirmed by immunohistochemistry in tumors derived from nestin $\mathrm{KD}$ cells, whereas nestin was abundantly expressed in tumors derived from vector control cells (Figure 3b). Consistent with our in vitro data, immunoreactivity for MMP3 was significantly increased in 
nestin KD tumors compared with vector controls, as confirmed by computer image analysis $(48.18 \pm 1.525$ versus $30.35 \pm 1.928$ ) (Figure 3b). Tumors derived from vector control cells were composed of nestin-high and MMP3-low melanoma cells that formed smooth bordered, uniformly circumscribed nodules that interfaced sharply with adjacent a

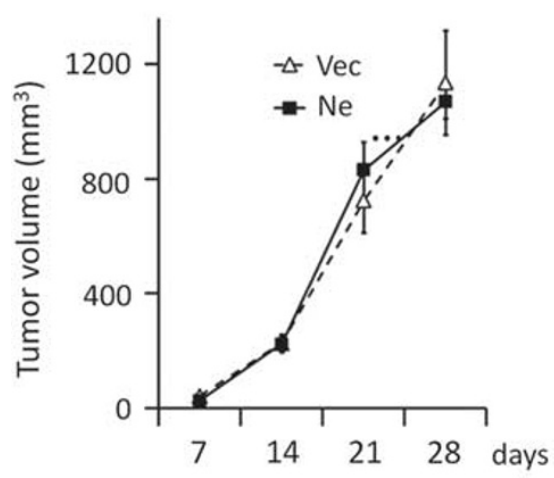

b

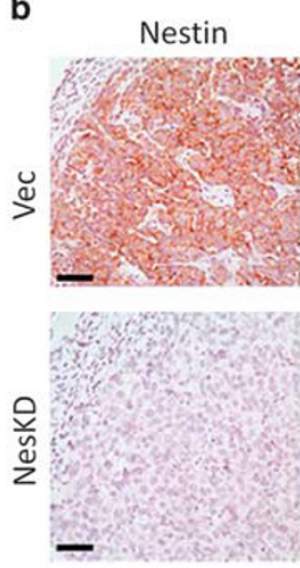

MMP3

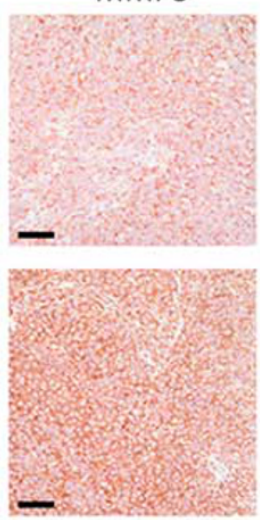

MMP3
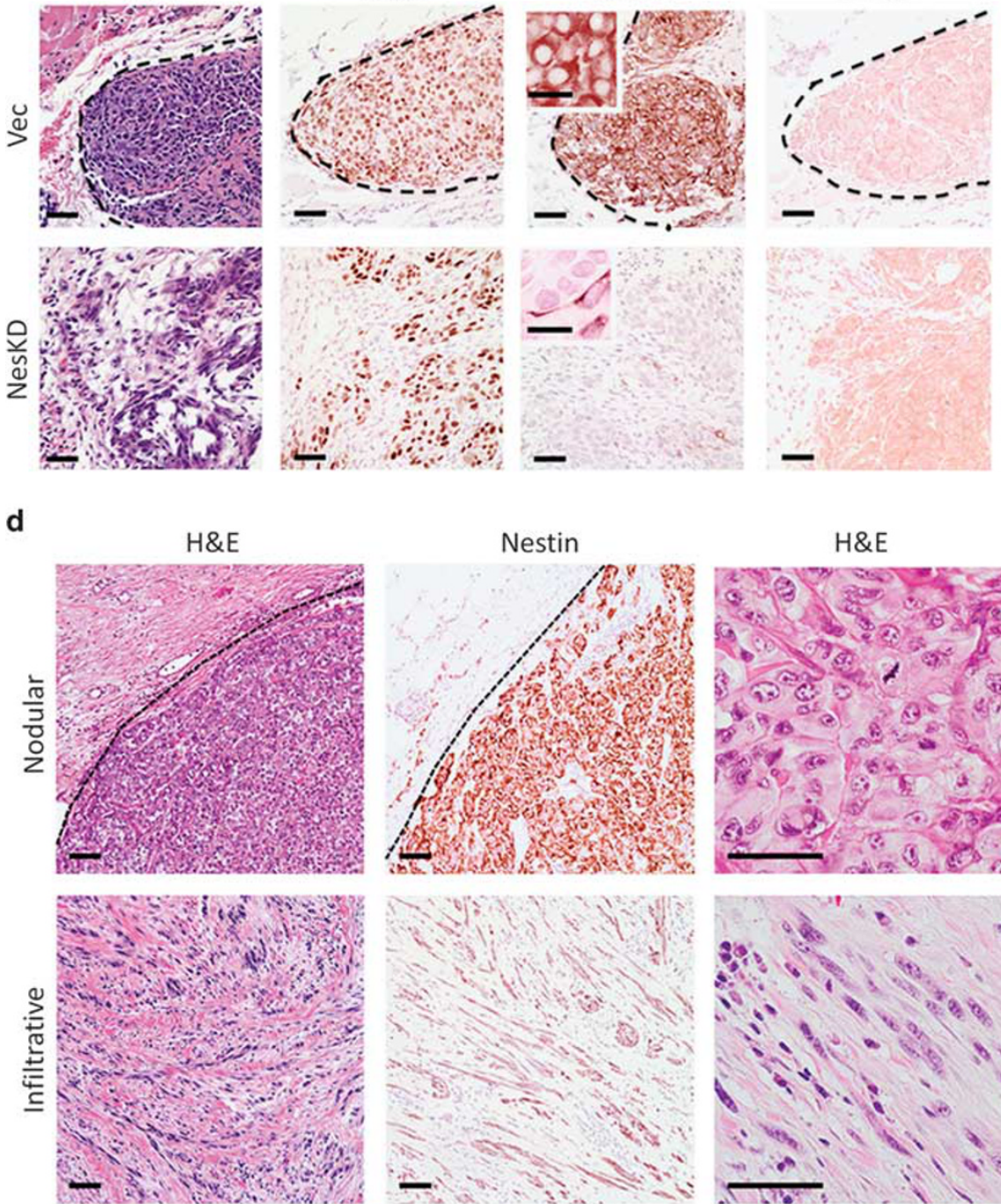

$H \& E$
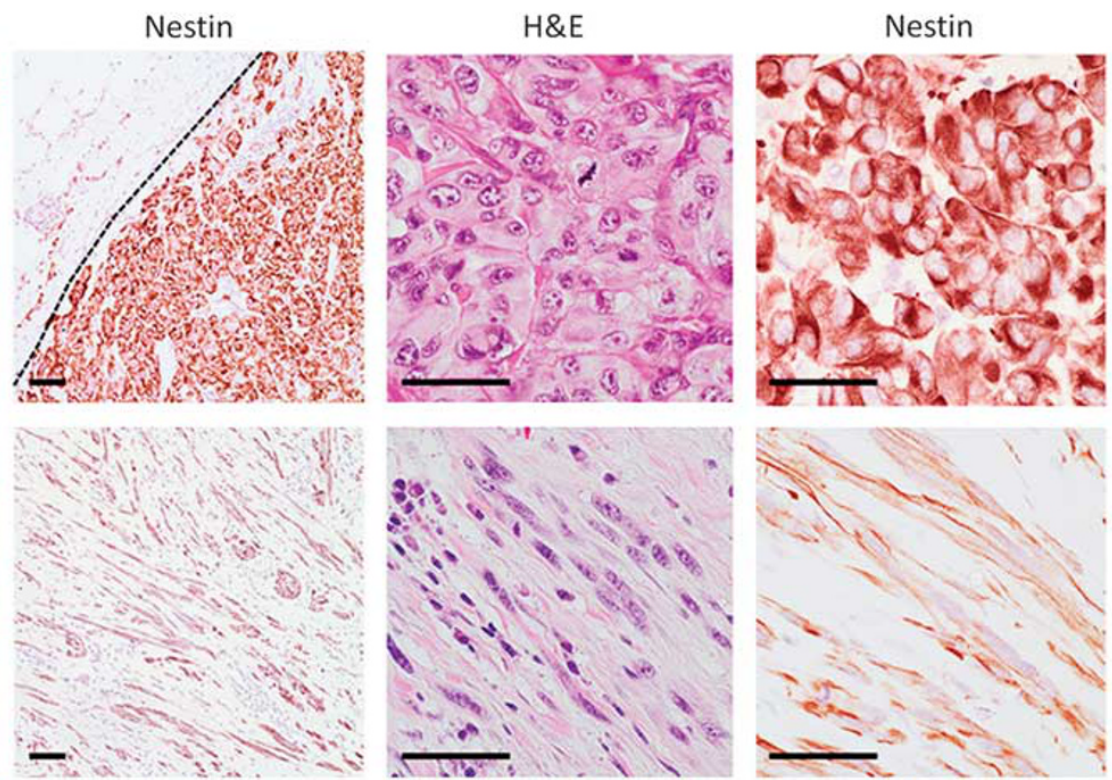

Figure 3 For caption please refer page 1390. 
stroma (Figure 3c). In contrast, tumors derived from nestin KD cells were comprised of nestin-low, MMP3-high melanoma cells that generated tumors with borders that focally were interrupted by jagged and irregular zones of early stromal invasion. The regions were prominent as early as 7 days after xenografting (Figure 3c), and the invasive relationship between tumor and adjacent stromal cells was further confirmed by intimate admixture of melanoma cells with CD31endothelial cells and F4/80-positive macrophages (Figure 3c).

\section{Nestin Expression Correlates with Infiltrative Patterns in Clinical Melanomas}

To determine whether nestin expression patterns seen in xenografts was reflected in clinical lesions, we first screened a small number of primary patient melanomas with tumorigenic (cohesive and expansive) growth patterns and found nestin to be abundantly expressed by immunohistochemistry throughout the cytoplasm of large rounded cells that formed cohesive tumor nodules $(N=5)$ (Figure $3 \mathrm{~d})$. In contrast, melanomas with predominantly infiltrative patterns (for example, desmoplastic melanomas) showed less prominent nestin reactivity that was primarily restricted to the sub-plasma membranous regions of cells $(N=5)$ (Figure 3d). These patterns were next evaluated in a larger cohort $(N=153)$ of patient melanomas represented in tissue microarray, where a prominent cytoplasmic pattern of nestin distribution was observed preferentially in nodules formed by cohesive rounded tumor cells (91 of $111 ; 82 \%$ ), and a weaker or mixed pattern was documented in infiltrative regions of melanomas composed of stroma-associated cells (42 of 42; $100 \%)(P<0.0001)$. To summarize, the trend was for the rounded cells that formed cohesive and expansive pattern melanoma nodules express strong nestin that was diffusely present throughout the cytoplasm of the majority of tumor cells. The often more fusiform cells that showed infiltrative patterns of stromal invasion, tended to contain many cells that expressed nestin in a peripheral, sub-membranous pattern, and therefore appeared overall to express less nestin by immunohistochemistry. Although TMA melanomas with characteristics of desmoplastic variants tended to be at the extreme end of this spectrum of submenbranous low-nestin expression, other less desmoplastic yet still infiltrative pattern melanomas showed an admixture of cells with low submembranous nestin and high cytoplasmic nestin (mixed pattern). These in vivo experimental and clinical data are consistent with our in vitro findings, implicating nestin and related MMP expression in tumorigenic and invasive melanoma phenotypes.

\section{Possible Mechanisms of Nestin Regulation of Melanoma Invasive Phenotype: pFAK and TGF- $\beta$}

Cancer cell invasion involves a complex series of highly orchestrated interactions involving alterations in cell shape and cytoskeletal structure, locomotion, cell-stromal adhesive properties, and protease secretion. FAK has a central role in cancer cell motility, adhesion, and invasion. ${ }^{43}$ In this regard, recent evidence indicates that nestin downregulation in prostate cancer cell lines triggers a switch from characteristic intracellular and submembranous clumped expression patterns of phosphorylated FAK (pFAK) to exclusive and punctate cell membrane localization that promotes integrin clustering and results in pFAK- and integrin-dependent matrix degradation and an invasive phenotype. ${ }^{14}$ In melanoma cells, we found nestin KD to be associated with lower pFAK and unaltered total FAK protein in A2058 cells, and increased pFAK and total FAK protein levels in A375 cells (Figure 4a). Despite these variations in protein expression, dual labeling revealed that nestin KD in both melanoma cell lines produced pFAK relocalization that was remarkably similar to the pro-invasive pattern described as a consequence of nestin $\mathrm{KD}$ in prostate cancer cell lines ${ }^{14}$ (Figure 4b). Specifically, the percentages of cells showing an exclusively membranous pattern increased as a function of nestin KD from 42.9 to $76.2 \%$, and 18.9 to $59.0 \%$ in A2058 and A375 cells, respectively $(P<0.001)$. Moreover, treatment with FAK inhibitor, PF-573228, did not significantly alter mRNA levels of MMP3 and MMP9 in A2058 and A375 cells, respectively (data not shown).

Figure 3 Nestin KD is associated with stromal invasion in vivo. (a) Tumors derived from A2058 nestin KD (NesKD, solid line) and vector control (Vec, dash line) cells had comparable growth rate in NOD-SCID mice at $3 \times 10^{6}$ cells/injection/mouse $(N=5)$. (b) Representative immunohistochemical staining of nestin and MMP3 in A2058 xenograft tumors at 28 days post grafting. Nestin KD tumors (bottom) had significantly enhanced MMP3 staining in the tumors confirmed with efficient nestin KD when compared with vector control tumors (top) where nestin was abundantly expressed (nestin KD, black bar; vector control, white bar; both $N=5, P<0.001$ ). Scale bars: $50 \mu \mathrm{m}$. (c) Representative H\&E and immunohistochemistry staining of vector control (top) and nestin KD (bottom) tumors at 7 days post xenografting. In contrast to well-circumscribed subcutaneous nodules of vector control tumors $(N=4)$, nestin KD tumors $(N=4)$ had significant stromal invasion in multiple areas. Immunoreactivity of SOX2 stained both A2058 vector control and nestin KD tumor cells. Efficient KD was confirmed in the nestin KD tumors. In contrast to dense cytoplasmic nestin staining in vector control tumors, a submembranous pattern of nestin distribution was observed in localized, spindle cells scattered in nestin KD tumors (inset). Nestin KD tumors had enhanced MMP3 staining. $\mathrm{CD} 31^{+}$vessels and $\mathrm{F} 4 / 80^{+}$dendritic cells appeared at peritumoral stroma of vector control tumors, whereas these cells diffusely infiltrated nestin KD tumors. Scale bars: $50 \mu \mathrm{m}$. (d) Examples of patterns of nestin expression that may be detected in tumorigenic (nodular, top) and infiltrative (desmoplastic, bottom) regions of certain human primary melanomas. Nodular regions by H\&E staining are wellcircumscribed (broken line: border between tumor (right) and adjacent stroma (left)) and composed of coalescent, rounded cells that express abundant cytoplasmic nestin by immunohistochemical staining. Infiltrative regions, in comparison, show diffuse permeation of stroma by elongated spindle-shaped cells that express quantitatively less nestin immunoreactivity that is localized to sub-plasma membrane regions. Scale bars: $50 \mu \mathrm{m}$. 
a

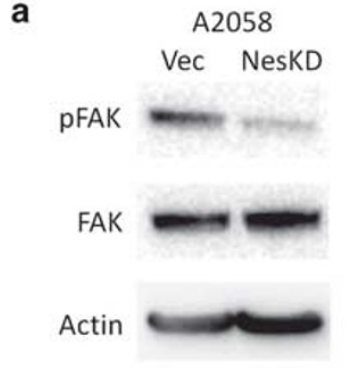

b

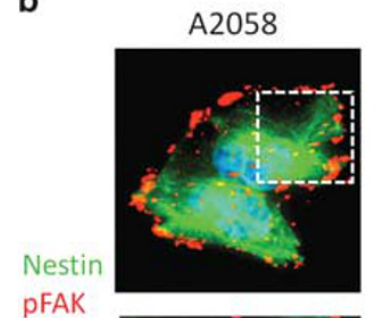

PFAK

Vec
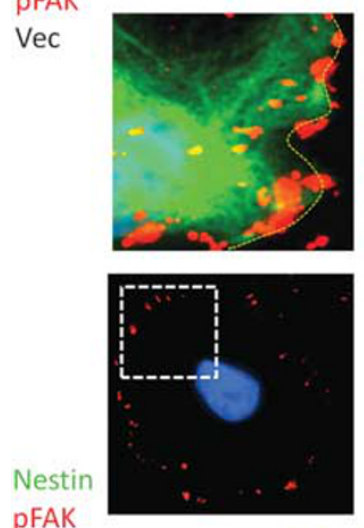

NesKD

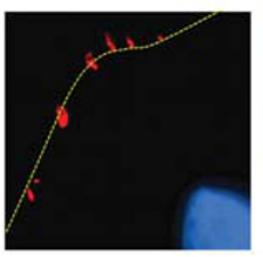

A375

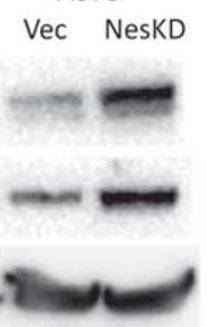

A375
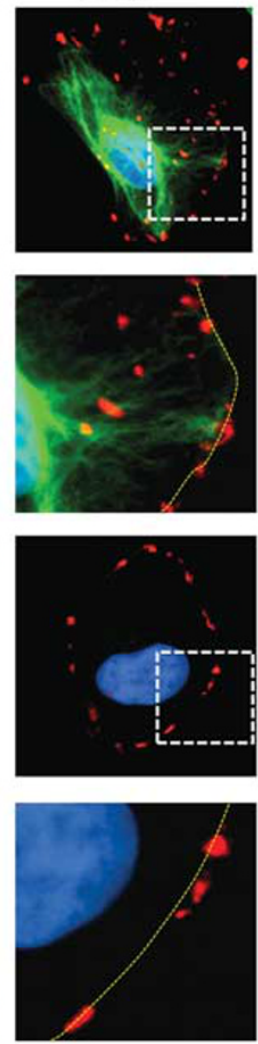

c

文

$\square$ Control

- TGF- $\beta$

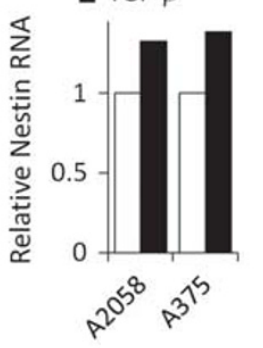

d

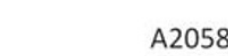

A2058

A375

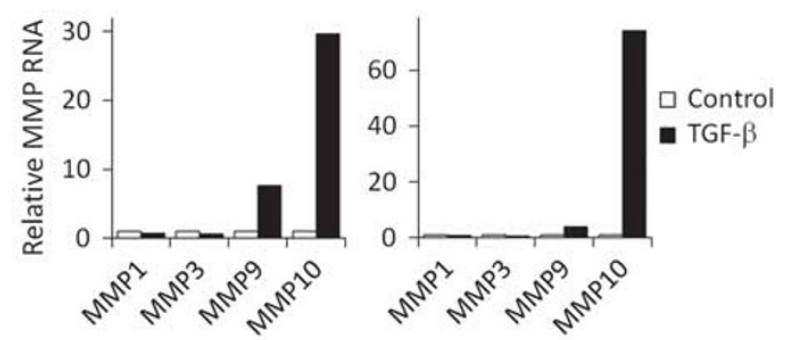

A375
A2058

e
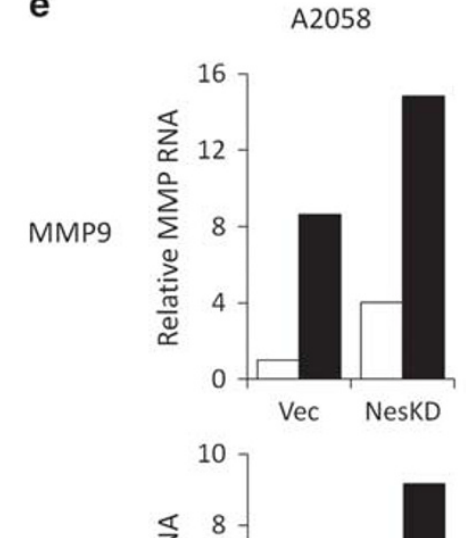

MMP10

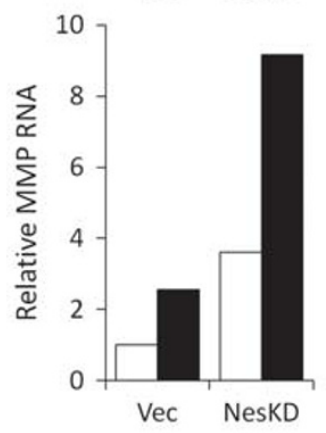

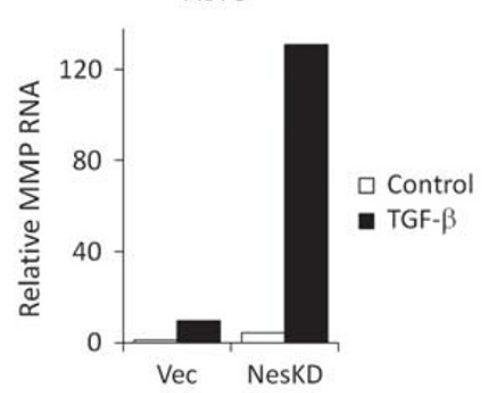

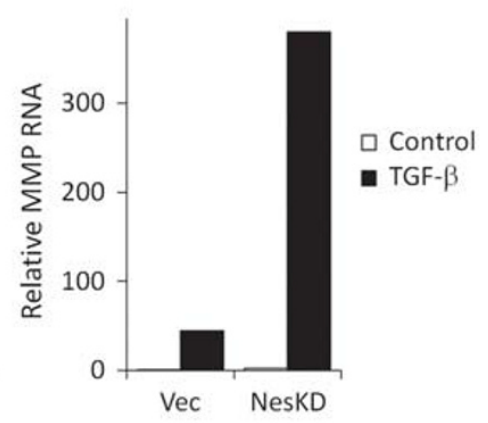

Figure 4 Possible mechanisms of nestin regulation of melanoma invasive phenotype: pFAK and TGF- $\beta$. (a) pFAK was significantly lower (78\% decrease) as a result of nestin KD in A2058 cells, whereas FAK protein levels were not changed (left panel); in contrast, pFAK and FAK were significantly higher (3.2-fold and 2.5-fold, respectively) as a result of nestin KD in A375 cells (right panel). (b) Intracellular expression pattern of phosphorylated FAK (pFAK, red) in vector control nestin (green)-expressing cells of both A2058 and A375 lines consisted of coarsely clumped intracellular and peripheral zones of immunoreactivity (upper panels, regions enclosed in broken square are shown at higher magnification directly beneath each panel; broken yellow lines approximate plasma membrane). In contrast, in nestin KD cells, pFAK was expressed as discrete punctate cell membrane-associated domains (bottom panels). (c) Nestin mRNA levels were not significantly altered by TGF- $\beta$ (black bars) in A2058 and A375 cells as compared with untreated cells (white bars). Average fold changes from at least two different batches of cells are shown. (d) Compared with untreated A2058 and A375 cells (white bars), TGF- $\beta$ (black bars) upregulated MMP9 and 10 mRNA levels, but did not alter mRNA levels of MMP1 and MMP3. Average fold changes from at least two different batches of cells are shown. (e) Compared with TGF- $\beta$-treated vector control cells, upregulation of MMP10 in A2058 nestin KD cells, and MMP9 and 10 in A375 nestin KD cells was significantly further amplified in the setting of nestin depletion.

FAK-dependent cancer cell transition to invasive phenotypes is known to involve TGF- $\beta,{ }^{44}$ an established driver of cancer virulence ${ }^{45}$ and melanoma invasiveness through the upregulation of MMPs. ${ }^{46}$ Of further interest, TGF- $\beta$ may directly influence nestin expression in pancreatic cancer cells. ${ }^{47}$ Although we did not find TGF- $\beta$ to significantly alter nestin mRNA expression in either A2058 or A375 cells (Figure 4c), it significantly upregulated MMP9 and 10 in A2058 and A375 cells, respectively (Figure 4d). Of interest, the effects of TGF- $\beta$ on the upregulation of MMP10 in A2058 cells, and MMP9 and10 in A375 cells were significantly more robust in the setting of nestin KD (Figure 4e). Specifically, 
among the TGF- $\beta$-treated cells, nestin KD A2058 cells had significantly upregulated MMP10, and nestin KD A375 cells had significantly upregulated MMP9 and 10, as compared with control cells (Figure 4e). These data suggest that although TGF- $\beta$ does not directly regulate nestin expression in the melanoma cell lines under study, TGF- $\beta$-mediated upregulation of certain MMPs is enhanced by low nestin expression.

\section{DISCUSSION}

Nestin is a type VI intermediate filament characteristically expressed in physiologic neural stem cells and muscle progenitor cells. ${ }^{48,49}$ Nestin regulates cell death in neural progenitor cells and podocytes of kidney ${ }^{50,51}$ and neuromuscular junction development ${ }^{52}$ by a CDK5-dependent mechanism. Although nestin has been associated with poor prognosis in both breast cancer and melanoma, ${ }^{53,54}$ it is not established that nestin is an authentic stem cell marker in cancer, and mechanisms that link degree of nestin expression with known behavior of clinical tumors remain largely unexplored. Melanoma has long been considered as a paradigm for the study of cancer behavior and progression. ${ }^{55}$ Primary melanomas may grow in either or both nodular and infiltrative patterns, ${ }^{2,4}$ the former more consistent with tumorigenesis driven by self-renewal, and the latter indicative of the ability of at least some cells to invade host tissues beyond the primary site. In this study, we asked whether nestin might relate to these two basic patterns of tumor growth. We find that nestin expression appears to correlate with these two potentially interchangeable phenotypes and provides potential mechanistic insights indicating that nestin regulates MMP production, a known mediator of the invasive growth phase of melanoma and other cancers.

Practically, clinical melanomas traditionally have been divided into subtypes based on presence and morphology of the radial growth phase and characteristics of vertical growth phase. Based on the cytology and architecture of the former, radial growth subtypes such as superficial spreading, lentigo maligna, acral lentiginous/mucosal have been designated. When radial growth fails to flank the invasive component for a span of three or more epidermal rete ridges, melanomas are considered to be of the nodular subtype. Moreover, when deeper invasion constituting vertical growth phase is composed of more infiltrative patterns of thin spindle cells, as opposed of expansive nodules of epithelioid cells, descriptors such as desmoplastic and sarcomatoid may be added to signify these features. In our study, the majority of human melanoma specimens were from a TMA without annotation as to subtype or outcome, such that the correlative morphology presented refers strictly to growth patterns (nodular versus infiltrative), rather than specific melanoma subtypes, their associated prognostic attributes, or relationship to patient survival.

The notion that cells forming tumorigenic nodules versus invasive fronts are fundamentally different is perhaps intuitive, as rounded cells that diffusely express cytoplasmic nestin and grow cohesively to form expansive nodules with little MMP expression are not physicodynamically or biochemically well-adapted to also navigate through spatial interstices and ECM barriers imposed by human dermis. Nonetheless, there exist conflicting studies that suggest that nestin expression mediates both three-dimensional tumorigenesis while at the same time driving an invasive phenotype. ${ }^{7,38}$ Cell-cell contact is known to influence kinetics of cancer cell invasion, ${ }^{56}$ and in this regard our approach differs from previous studies by using melanoma cell-loading doses for Matrigel invasion assays that were lower by fourfold. ${ }^{7}$ In addition, our KD strategy useded a shRNA construct that did not significantly alter melanoma cell proliferation, an additional potential factor in interpretation of such assays. In this regard, it is important to separate overall proliferation in bulk cell culture, which in our study was not affected by nestin $\mathrm{KD}$, from nestin $\mathrm{KD}$-induced inhibition of sphere formation that has been presumed to be driven by a selfrenewing stem cell subcompartment. Moreover, our findings of enhanced invasion as a function of nestin KD are supported by both demonstration of induction of MMPs known to facilitate this process, ${ }^{39,57}$ and by the ability to partially block this effect using specific ${ }^{31}$ and broad-spectrum ${ }^{32} \mathrm{MMP}$ inhibitors. The concept of reciprocal switching between tumorigenic and invasive melanoma phenotypes is fortified further by recent studies by Hoek et al ${ }^{58}$ who have provided complementary in vitro and in vivo evidence based on experimental downregulation of microphthalmia-associated transcription factor gene expression. Because cancer cells may co-opt pathways integral to embryogenesis, ${ }^{59}$ it also is of interest that our findings in melanoma bear some resemblance to the phenomenon where stationary proliferating nestin-expressing neural crest stem cells lose nestin ${ }^{8}$ as they acquire MMP expression ${ }^{60}$ in conjunction with migration and differentiation. Finally, we noted no increase in TIMP1-4 expression with nestin KD in A2058 cells or in TIMP1-3 in A375 cells, suggesting that the biological effects of increased MMP expression by nestin KD may be independent of many of their primary endogenous inhibitors.

It is of interest that although nestin KD failed to increase cell motility, cell invasion was enhanced. While our data do not provide fundamental insight in this regard, it is noteworthy that migration on a surface involves coordinated ability to loosen from adhesive interactions with adjacent cells mediated by cell adhesion molecules, gain traction with substrate through the expression of integrins, and contract and expand via regulation of the actin-myosin complex. Invasion, on the other hand, requires additional assets, such as production of invasopodia that mediate initial proteolysis of ECM, and more focused proteolysis attained primarily via production of MMPs. Clearly, the dominance of proteolysis over movement could produce situations whereby less motile cells are in fact more invasive. The prospect that less motile yet invasive cells might be better equipped to form metastases 
is a fascinating one, as the ability to shift from an invasive to a tumorigenic phenotype could be favored by immigrant cells capable of 'planting' themselves in the metastatic niche upon arrival, a behavior conceivably favored by low migratory potential upon reaching their destination.

Mechanistically, the interactions between nestin and MMP expression are likely to be complex and involve multiple pathways. One insight in the present study into the effects of nestin expression on the invasive phenotype was provided by cell labeling for pFAK. Hyder et $a l^{14}$ have recently observed that nestin downregulation in prostate cancer cell lines results in repositioning of pFAK from clumped cytoplasmic and submembranous regions to discrete punctate domains that exclusively decorate the cell membrane, and our findings in both A2058 and A375 nestin KD melanoma lines are remarkably similar. In contrast, pharmacological inhibition of FAK did not significantly alter MMP expression in the melanoma lines examined. Although this raises the possibility that invasive pathways involving FAK/integrinmediated cell/matrix adhesion may also be involved in nestin $\mathrm{KD}$ cells, ${ }^{61-63}$ our data is too preliminary to draw definitive conclusions at this juncture. FAK also is known to be involved in TGF- $\beta$ adhesion-dependent signaling and MMP upregulation. ${ }^{44,64}$ Moreover, melanoma cells and their microenvironment may constitutively secrete bioactive TGF- $\beta^{65,66}$ Although the upstream regulatory mechanisms for nestin expression remain largely unknown, ${ }^{67}$ a number of studies suggest that nestin itself may be influenced by extracellular stimuli ${ }^{29,30,47,68}$ such as TGF- $\beta$. Our data suggest that although TGF- $\beta$ does not influence nestin expression, the expression of certain MMPs is enhanced by TGF- $\beta$ in association with nestin KD. TGF- $\beta$ is abundantly expressed in human epidermis and dermis, ${ }^{69}$ and the possibility exists that it may serve as a microenvironmental stimulus to drive MMP expression in melanoma cells with low nestin, thus facilitating invasion. Nonetheless, our data also indicate that nestin also has TGF- $\beta$-independent functions. Additional studies are now indicated to better understand the molecular linkages between microenvironment, nestin, MMPs, FAK, and stromal invasion. ${ }^{70}$

In summary, our data support a reciprocal relationship between expression of nestin and certain MMPs important in transition to an invasive phenotype, and begin to probe molecular mechanisms potentially involved in nestin/MMP interactions. Although none of the assays used or mechanisms explored permit a definitive conclusion of a 'nestin/ MMP invasive switch', the findings provide a framework for understanding nestin function in melanoma biology. Moreover, the results obtained are internally consistent in supporting a role for nestin in the, as yet, unsolved mystery of how melanomas express a complementary duality involving tumorigenic and invasive growth in a manner that appears to synergize to drive virulence. Practically, nestin immunohistochemistry of patient biopsies has focused to date on correlating the intensity of its expression with aggressive behavior, $7,53,54$ as assessed by the formation of durable metastases or their clinical consequences. This now must be re-examined in the context of a more complex nestin profile where variation in nestin expression may define subpopulations differentially capable of the tumorigenic or invasive growth that likely must collaborate to spawn clinically significant metastases. Because the nestin-rich tumorigenic growth phase likely requires coordinated and bidirectional interaction with the nestin-poor infiltrative phase in order to drive tumor dissemination, studies are also indicated to screen for the effects of endogenous pathophysiologic mediators that are abundant in the melanoma stromal microenvironment ${ }^{71}$ and that may be capable of influencing nestin expression. Translationally, nestin transcription is known to be epigenetically regulated by histone acetylation that itself may be influenced by retinoic acid, ${ }^{72}$ an agent known to inhibit melanoma virulence-associated gene expression. ${ }^{73}$ Accordingly, biological modifiers of nestin expression should now be further examined in the context of melanoma therapeutics.

Supplementary Information accompanies the paper on the Laboratory Investigation website (http://www.laboratoryinvestigation.org)

\section{ACKNOWLEDGMENTS}

We thank Professor Bernard A. Rosner, Harvard Catalyst (The Harvard Clinical and Translational Science Center; National Center for Research Resources and the National Center for Advancing Translational Sciences, National Institutes of Health Award 8UL1TR000170-05 and financial contributions from Harvard University and its affiliated academic health care centers) for advice in statistical analysis. The content is solely the responsibility of the authors and does not necessarily represent the official views of Harvard Catalyst, Harvard University and its affiliated academic health care centers, or the National Institutes of Health. This work was supported by NIH grants R01 CA158467 (GFM and MHF), 5P50CA093683-09 (TS), and training grants T32AR007098-38 (AL), 5T32HL7627-29 (CWL), and 2T32AR7098-37 (JM). TS is the recipient of a Research Career Development Award from the Dermatology Foundation and an Innovative Research Grant from the Melanoma International Foundation. GFM, CWL and QZ conceived of and designed the study, and CWL and QZ performed most experiments. GFM, $\mathrm{CL}$, and JYL selected patient specimens. MHF, SK, CWL, JM, TS, and QZ performed animal experiments. JH, CL, JYL, and MTW provided technical support. GFM and $\mathrm{CL}$ evaluated patient and animal specimens independently. CWL, AL, and PIL performed statistical analysis. CWL and GFM wrote the manuscript.

\section{DISCLOSURE/CONFLICT OF INTEREST}

The authors declare no conflict of interest.

1. Gialeli C, Theocharis AD, Karamanos NK. Roles of matrix metalloproteinases in cancer progression and their pharmacological targeting. FEBS J 2011;278:16-27.

2. Guerry Dt, Synnestvedt $M$, Elder $D E$, et al. Lessons from tumor progression: the invasive radial growth phase of melanoma is common, incapable of metastasis, and indolent. J Invest Dermatol 1993;100:342S-345S.

3. Hofmann UB, Eggert AA, Blass $K$, et al. Expression of matrix metalloproteinases in the microenvironment of spontaneous and experimental melanoma metastases reflects the requirements for tumor formation. Cancer Res 2003;63:8221-8225.

4. Laga AC, Murphy GF. Cellular heterogeneity in vertical growth phase melanoma. Arch Pathol Lab Med 2010;134:1750-1757. 
5. Yan C, Boyd DD. Regulation of matrix metalloproteinase gene expression. J Cell Physiol 2007;211:19-26.

6. Maeda E, Sugimoto M, Ohashi T. Cytoskeletal tension modulates MMP1 gene expression from tenocytes on micropillar substrates. J Biomech 2013;46:991-997.

7. Akiyama $M$, Matsuda $Y$, Ishiwata $T$, et al. Inhibition of the stem cell marker nestin reduces tumor growth and invasion of malignant melanoma. J Invest Dermatol 2013;133:1384-1387.

8. Wiese C, Rolletschek A, Kania G, et al. Nestin expression-a property of multi-lineage progenitor cells? Cell Mol Life Sci 2004;61:2510-2522.

9. Klein $\mathrm{WM}, \mathrm{Wu} B P$, Zhao $\mathrm{S}$, et al. Increased expression of stem cell markers in malignant melanoma. Mod Pathol 2007:20:102-107.

10. Schatton T, Murphy GF, Frank NY, et al. Identification of cells initiating human melanomas. Nature 2008:451:345-349.

11. Boiko AD, Razorenova OV, van de Rijn M, et al. Human melanomainitiating cells express neural crest nerve growth factor receptor CD271. Nature 2010;466:133-137.

12. Girouard SD, Murphy GF. Melanoma stem cells: not rare, but well done. Lab Invest 2011;91:647-664.

13. Laga AC, Zhan $\mathrm{Q}$, Weishaupt $\mathrm{C}$, et al. SOX2 and nestin expression in human melanoma: an immunohistochemical and experimental study. Exp Dermatol 2011;20:339-345.

14. Hyder CL, Lazaro G, Pylvanainen JW, et al. Nestin regulates prostate cancer cell invasion by influencing FAK and integrin localisation and functions. J Cell Sci 2014;127:2161-2173.

15. Girouard SD, Laga AC, Mihm MC, et al. SOX2 contributes to melanoma cell invasion. Lab Invest 2012;92:362-370.

16. Jouhilahti EM, Peltonen $\mathrm{S}$, Callens $\mathrm{T}$, et al. The development of cutaneous neurofibromas. Am J Pathol 2011;178:500-505.

17. Jarvinen $T M$, Kanninen $P$, Jeskanen $L$, et al. Matrix metalloproteinases as mediators of tissue injury in different forms of cutaneous lupus erythematosus. Br J Dermatol 2007;157:970-980.

18. Sonoda $Y$, Matsumoto $Y$, Funakoshi $M$, et al. Anti-apoptotic role of focal adhesion kinase (FAK). Induction of inhibitor-of-apoptosis proteins and apoptosis suppression by the overexpression of FAK in a human leukemic cell line, HL-60. J Biol Chem 2000;275: 16309-16315.

19. Austyn JM, Gordon S. F4/80, a monoclonal antibody directed specifically against the mouse macrophage. Eur J Immunol 1981;11 805-815.

20. Lu $P, L i L$, Kuno $K$, et al. Protective roles of the fractalkine/CX3CL1CX3CR1 interactions in alkali-induced corneal neovascularization through enhanced antiangiogenic factor expression. J Immunol 2008;180:4283-4291.

21. Young L, Sung J, Stacey G, et al. Detection of Mycoplasma in cell cultures. Nat Protoc 2010:5:929-934.

22. Xu DS, Yang C, Proescholdt $M$, et al. Neuronatin in a subset of glioblastoma multiforme tumor progenitor cells is associated with increased cell proliferation and shorter patient survival. PLoS One 2012;7:e37811.

23. Thomay AA, Daley JM, Sabo E, et al. Disruption of interleukin-1 signaling improves the quality of wound healing. Am J Pathol 2009;174:2129-2136.

24. Corthorn J, Rey S, Chacon C, et al. Spatio-temporal expression of MMP2, MMP-9 and tissue kallikrein in uteroplacental units of the pregnant guinea-pig (Cavia porcellus). Reprod Biol Endocrinol 2007;5:27.

25. Doehn U, Hauge C, Frank SR, et al. RSK is a principal effector of the RAS-ERK pathway for eliciting a coordinate promotile/invasive gene program and phenotype in epithelial cells. Mol Cell 2009;35:511-522.

26. Hahn WC, Dessain SK, Brooks MW, et al. Enumeration of the simian virus 40 early region elements necessary for human cell transformation. Mol Cell Biol 2002;22:2111-2123.

27. Larson AR, Lee CW, Lezcano $C$, et al. Melanoma spheroid formation involves laminin-associated vasculogenic mimicry. Am J Pathol 2014;184:71-78.

28. Pastrana E, Silva-Vargas V, Doetsch F. Eyes wide open: a critical review of sphere-formation as an assay for stem cells. Cell Stem Cell 2011:8:486-498.

29. Delcroix GJ, Curtis KM, Schiller PC, et al. EGF and bFGF pre-treatment enhances neural specification and the response to neuronal commitment of MIAMI cells. Differentiation 2010;80:213-227.

30. Huang $\mathrm{YL}$, Shi GY, Jiang MJ, et al. Epidermal growth factor upregulates the expression of nestin through the Ras-Raf-ERK signaling axis in rat vascular smooth muscle cells. Biochem Biophys Res Commun 2008;377:361-366.

31. Fray MJ, Dickinson RP. Discovery of potent and selective succinyl hydroxamate inhibitors of matrix metalloprotease-3 (stromelysin-1). Bioorg Med Chem Lett 2001;11:571-574.

32. Rasmussen HS, McCann PP. Matrix metalloproteinase inhibition as a novel anticancer strategy: a review with special focus on batimastat and marimastat. Pharmacol Ther 1997;75:69-75.

33. Ma J, Lin JY, Alloo A, et al. Isolation of tumorigenic circulating melanoma cells. Biochem Biophys Res Commun 2010;402:711-717.

34. Lian CG, Xu Y, Ceol C, et al. Loss of 5-hydroxymethylcytosine is an epigenetic hallmark of melanoma. Cell 2012;150:1135-1146.

35. Laga AC, Lai CY, Zhan Q, et al. Expression of the embryonic stem cell transcription factor SOX2 in human skin: relevance to melanocyte and merkel cell biology. Am J Pathol 2010;176:903-913.

36. Kaufmann WK, Nevis KR, Qu P, et al. Defective cell cycle checkpoint functions in melanoma are associated with altered patterns of gene expression. J Invest Dermatol 2008;128:175-187.

37. Matsuda $Y$, Naito Z, Kawahara K, et al. Nestin is a novel target for suppressing pancreatic cancer cell migration, invasion and metastasis. Cancer Biol Ther 2011;11:512-523.

38. Kleeberger W, Bova GS, Nielsen ME, et al. Roles for the stem cell associated intermediate filament Nestin in prostate cancer migration and metastasis. Cancer Res 2007;67:9199-9206.

39. Kessenbrock K, Plaks V, Werb Z. Matrix metalloproteinases: regulators of the tumor microenvironment. Cell 2010;141:52-67.

40. Schatton T, Frank MH. The in vitro spheroid melanoma cell culture assay: cues on tumor initiation? J Invest Dermatol 2010;130:1769-1771.

41. Kumar SM, Liu S, Lu H, et al. Acquired cancer stem cell phenotypes through Oct4-mediated dedifferentiation. Oncogene 2012;31:4898-4911.

42. Chakraborti $S$, Mandal $M$, Das $S$, et al. Regulation of matrix metalloproteinases: an overview. Mol Cell Biochem 2003;253:269-285.

43. Schlaepfer DD, Mitra SK. Multiple connections link FAK to cell motility and invasion. Curr Opin Genet Dev 2004;14:92-101.

44. Cicchini C, Laudadio I, Citarella F, et al. TGFbeta-induced EMT requires focal adhesion kinase (FAK) signaling. Exp Cell Res 2008;314:143-152.

45. Polyak K, Weinberg RA. Transitions between epithelial and mesenchymal states: acquisition of malignant and stem cell traits. Nat Rev Cancer 2009;9:265-273.

46. Janji B, Melchior C, Gouon V, et al. Autocrine TGF-beta-regulated expression of adhesion receptors and integrin-linked kinase in HT-144 melanoma cells correlates with their metastatic phenotype. Int J Cancer 1999;83:255-262.

47. Su HT, Weng CC, Hsiao PJ, et al. Stem cell marker nestin is critical for TGF-beta1-mediated tumor progression in pancreatic cancer. Mol Cancer Res 2013;11:768-779.

48. Chang L, Goldman RD. Intermediate filaments mediate cytoskeletal crosstalk. Nat Rev Mol Cell Biol 2004:5:601-613.

49. Gilyarov AV. Nestin in central nervous system cells. Neurosci Behav Physiol 2008;38:165-169.

50. Liu W, Zhang Y, Hao J, et al. Nestin protects mouse podocytes against high glucose-induced apoptosis by a Cdk5-dependent mechanism. J Cell Biochem 2012;113:3186-3196.

51. Sahlgren CM, Pallari HM, He T, et al. A nestin scaffold links Cdk5/ p35 signaling to oxidant-induced cell death. EMBO J 2006;25: 4808-4819.

52. Yang J, Dominguez B, de Winter $F$, et al. Nestin negatively regulates postsynaptic differentiation of the neuromuscular synapse. Nat Neurosci 2011:14:324-330.

53. Piras F, Perra MT, Murtas D, et al. The stem cell marker nestin predicts poor prognosis in human melanoma. Oncol Rep 2010;23:17-24.

54. Piras F, lonta MT, Lai $\mathrm{S}$, et al. Nestin expression associates with poor prognosis and triple negative phenotype in locally advanced (T4) breast cancer. Eur J Histochem 2011;55:e39.

55. Clark Jr. WH, Ainsworth AM, Bernardino EA, et al. The developmental biology of primary human malignant melanomas. Semin Oncol 1975;2:83-103.

56. Cui $\mathrm{Y}$, Yamada S. N-cadherin dependent collective cell invasion of prostate cancer cells is regulated by the $\mathrm{N}$-terminus of alpha-catenin. PLoS One 2013;8:e55069.

57. lida J, McCarthy JB. Expression of collagenase-1 (MMP-1) promotes melanoma growth through the generation of active transforming growth factor-beta. Melanoma Res 2007;17:205-213. 
58. Hoek KS, Eichhoff OM, Schlegel NC, et al. In vivo switching of human melanoma cells between proliferative and invasive states. Cancer Res 2008;68:650-656.

59. Topczewska JM, Postovit LM, Margaryan NV, et al. Embryonic and tumorigenic pathways converge via Nodal signaling: role in melanoma aggressiveness. Nat Med 2006;12:925-932.

60. Kuriyama S, Mayor R. Molecular analysis of neural crest migration. Philos Trans R Soc Lond B Biol Sci 2008;363:1349-1362.

61. Wang $Y$, McNiven MA. Invasive matrix degradation at focal adhesions occurs via protease recruitment by a FAK-p130Cas complex. J Cell Bio 2012;196:375-385.

62. Kim M, Gans JD, Nogueira C, et al. Comparative oncogenomics identifies NEDD9 as a melanoma metastasis gene. Cell 2006;125:1269-1281.

63. Deramaudt TB, Dujardin D, Hamadi A, et al. FAK phosphorylation at Tyr-925 regulates cross-talk between focal adhesion turnover and cel protrusion. Mol Biol Cell 2011;22:964-975.

64. Thannickal VJ, Lee DY, White ES, et al. Myofibroblast differentiation by transforming growth factor-beta1 is dependent on cell adhesion and integrin signaling via focal adhesion kinase. J Biol Chem 2003;278: 12384-12389.

65. Wakefield LM, Smith DM, Masui T, et al. Distribution and modulation of the cellular receptor for transforming growth factor-beta. J Cell Bio 1987:105:965-975.
66. Tulley S, Chen WT. Transcriptional Regulation of Seprase in Invasive Melanoma Cells by Transforming Growth Factor-beta Signaling. J Biol Chem 2014;289:15280-15296.

67. Ishiwata T, Matsuda Y, Naito Z. Nestin in gastrointestinal and other cancers: effects on cells and tumor angiogenesis. World J Gastroenterol 2011;17:409-418.

68. Loo DT, Althoen MC, Cotman CW. Down regulation of nestin by TGFbeta or serum in SFME cells accompanies differentiation into astrocytes. Neuroreport 1994;5:1585-1588.

69. Quan T, He T, Kang S, et al. Ultraviolet irradiation alters transforming growth factor beta/smad pathway in human skin in vivo. J Invest Dermatol 2002;119:499-506.

70. Croft DR, Olson MF. Regulating the conversion between rounded and elongated modes of cancer cell movement. Cancer Cell 2008:14:349-351.

71. Lezcano C, Lee CW, Larson AR, et al. Evaluation of stromal HGF immunoreactivity as a biomarker for melanoma response to RAF inhibitors. Mod Pathol 2014;27:1193-1202.

72. Han DW, Do JT, Arauzo-Bravo MJ, et al. Epigenetic hierarchy governing Nestin expression. Stem Cells 2009;27:1088-1097.

73. Estler M, Boskovic G, Denvir J, et al. Global analysis of gene expression changes during retinoic acid-induced growth arrest and differentiation of melanoma: comparison to differentially expressed genes in melanocytes vs melanoma. BMC Genomics 2008;9:478. 